\title{
PRINCIPIOS GENERALES DE UNA SOCIEDAD LIBRE PARA FORTALECER EL ORDEN ESPONTÁNEO DEL MERCADO
}

\author{
GENERAL PRINCIPLES OF A FREE SOCIETY FOR SPONTANEOUS ORDER \\ TO STRENGTHEN THE MARKET \\ VLADIMIR RodRÍGUEZ CAIRo* \\ Docente Asociado de la Facultad de Ciencias Contables \\ Universidad Nacional Mayor de San Marcos - UNMSM / Lima - Perú \\ [Recepción: Setiembre de 2015/ Conformidad: Octubre 2015]
}

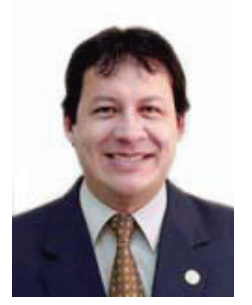

\section{RESUMEN}

El presente estudio aborda los principios generales de una sociedad libre referidos a la tradición de la libertad individual, la justicia y el gobierno limitado. Busca responder la siguiente interrogante: ¿Por qué el orden espontáneo del mercado requiere la reivindicación de dichos principios?

En ese sentido, cabe precisar que la naturaleza del estudio es de tipo explicativo. Del mismo modo, el método de investigación utilizado es el analítico. Asimismo, se recurrieron a fuentes bibliográficas que sustentan los principios esenciales de una sociedad libre y el orden espontáneo del mercado.

Para una mejor comprensión del tema propuesto, el contenido se ha estructurado en tres partes: La primera comprende los antecedentes; en la segunda, se plantea el orden espontáneo del mercado y la tercera abarca los principios generales de una sociedad libre. Luego, se presentan las conclusiones y finalmente, se da a conocer la bibliografía.

\section{Palabras clave:}

Principios generales; sociedad libre; orden espontáneo; mercado.

\begin{abstract}
This study addresses the general principles of a free society referring to the tradition of individual freedom, justice and limited government. It seeks to answer the question: Why does the spontaneous market order require the vindication of those principles?

In that regard, it should be noted that the nature of the study is of explanatory type. Thus, the research method used is analytical. Similarly, the literature sources which support the essential principles of a free society and the spontaneous market order were consulted. For a better understanding of the proposed theme, the content is structured in three parts. The first comprises the background. In the second the spontaneous market order is explained. The third covers the general principles of a free society. Then the conclusions. Finally, the literature is mentioned.
\end{abstract}

\section{Keywords:}

General principles; free society; spontaneous order; market.

\footnotetext{
* Doctor en Derecho y Ciencia Política. Magíster en Finanzas - UNMSM. Email: vladirodriguezcairo@yahoo.es
} 


\section{INTRODUCCIÓN}

Los principios generales de una sociedad libre se inspiran en la importancia superior de la libertad individual, la justicia y el gobierno limitado. Es así que, para fortalecer el orden espontáneo del mercado se requiere que el gobierno, en sus funciones coercitivas, se limite a establecer prohibiciones como reglas abstractas, de tal forma que puedan aplicarse igualmente a todos los grupos sociales. Además de ello, es importante que se establezcan ciertos límites al poder de los gobiernos de turno. En estricto, nuestro país, requiere reivindicar los principios de una sociedad libre para promover de manera efectiva el desarrollo de nuestra sociedad.

De acuerdo con lo sostenido por Friedrich von Hayek, el orden espontáneo se basa en reglas abstractas que dejan libres a los individuos para que hagan uso de sus conocimientos orientados a sus propios fines. No obstante, una organización es un ordenamiento formado por el diseño humano y se basa en mandatos específicos. En ese mismo sentido, añade que el desarrollo de reglas universales de conducta no se inicia en el interior de la comunidad organizada de la tribu, sino más bien, con el primer caso de trueque tácito, en el que un salvaje puso una cierta oferta en el límite del territorio de su tribu con la esperanza de que llegase del mismo modo una oferta en respuesta, iniciando así una nueva costumbre.

De este modo, el orden espontáneo del mercado, en particular, no descansa en propósitos comunes sino en la reciprocidad (reconciliación de propósitos diferentes para el beneficio mutuo de los participantes). La sociedad evoluciona en el tiempo, lo mismo ha sucedido con el lenguaje (nadie lo creó), la moneda (solo existía porque habían seres humanos comer- ciando, hasta que aparecieron los bancos centrales), el mercado (la tendencia de los hombres a intercambiar surge de la propia naturaleza humana que induce a los hombres al trueque de sus bienes), el Derecho (nace con el reclamo porque se incumple un contrato o se produce un daño), entre otros casos.

Dentro de este contexto, el objetivo del estudio consiste en explicar la necesidad de reivindicar aquellos principios de una sociedad libre referidos a la tradición de la libertad individual, la justicia y el gobierno limitado para fortalecer el orden espontáneo del mercado, debido a que el intercambio en el mercado es el que nos permite precisamente ir elevando nuestro nivel de bienestar, y para tal efecto, el gobierno no debe distorsionar las relaciones de intercambio en el mercado.

\section{ANTECEDENTES: PRAXEOLOGÍA, ECONOMÍAY CATALÁCTICA}

Ludwig von Mises ${ }^{1}$ argumenta (2011: 4-5) que de la Economía Política elaborada por la escuela clásica ${ }^{2}$ emergía la Teoría General de la Acción Humana, la Praxeología ${ }^{3}$. Los problemas económicos o catalácticos ${ }^{4}$ quedaban enmarcados en una ciencia más general, integración imposible ya de alterar. Todo estudio económico debe partir de actos que consisten en optar y preferir; la Economía es una parte, si bien la más elaborada hasta ahora, de una ciencia más universal, la Praxeología.

A modo de sistematización, el siguiente diagrama permite comprender que Mises se enfoca en describir el fenómeno cataláctico, como parte de la Economía, y ésta a su vez, dentro de una ciencia más general, que es la Praxeología.

1 Ludwig Heinrich Edler von Mises (Lemberg 1881 - Nueva York 1973) fue un economista austriaco de origen judío, historiador, filósofo y escritor liberal que tuvo una influencia significativa en el moderno movimiento libertario en pro del mercado libre y en la Escuela Austríaca. Pensaba que los mercados así como los pueblos deberían liberarse de la intromisión de los gobiernos.

2 La economía política (lo que hoy conocemos por economía), considerada como una rama de la ciencia del hombre de Estado o legislador, se plantea dos objetivos distintos: en primer lugar, (...) que el pueblo pueda conseguir ese ingreso, o esa subsistencia por sí mismo; y en segundo lugar, proporcionar al Estado o comunidad un ingreso suficiente para pagar los servicios públicos (Smith 2011: 539).

3 Del griego: Praxis = acción; Logos = entendimiento. Teoría General de la Acción Humana. Fue empleado por primera vez en 1890 por Espinas (no es un término original de Mises). El objeto de estudio de la praxeología es la acción humana como tal y no los motivos que mueven a la gente a actuar (ese es campo de la Psicología).

El Derecho también está dentro del ámbito de la praxeología, lo mismo sucede con las demás ciencias sociales.

4 Del griego: Katallattein = canjear, permutar. Teoría General del Intercambio en el Mercado (determinación de precios). Ciencia de los Intercambios. Esto es lo que Mises entiende por Economía.

126/ QVIPURAMAYOC|Vol. 23(44) 2015 


\section{Diagrama No 01}

Relación entre Praxeología, Economía y Cataláctica

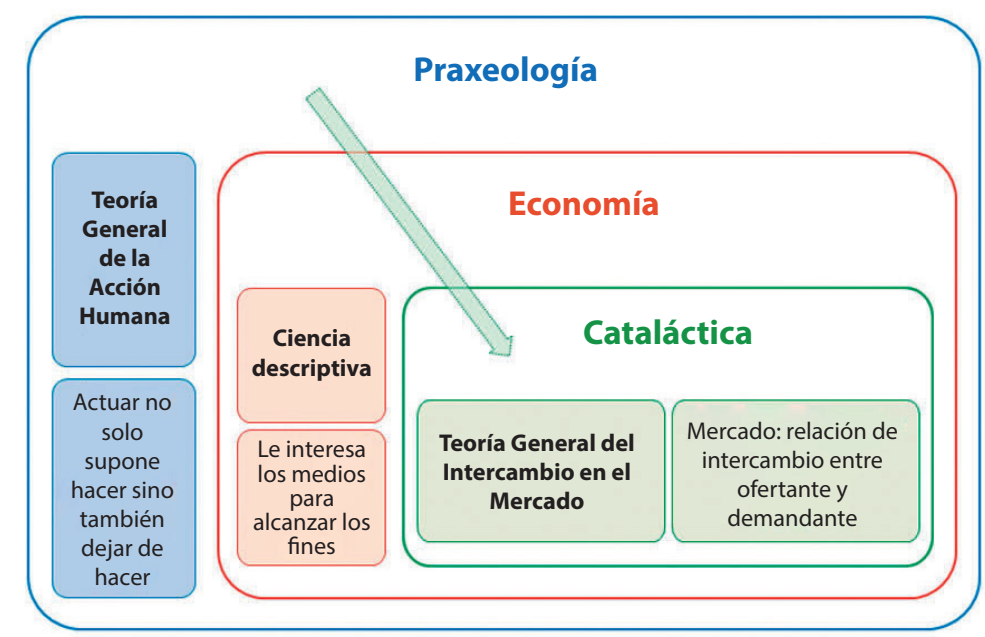

Fuente: Elaboración propia.

Debe enfatizarse que para Mises la acción (humana) no consiste simplemente en preferir (...) quien solo desea y espera no interviene activamente en el curso de los acontecimientos ni en la plasmación de su destino. El hombre, en cambio, al actuar opta, determina y procura alcanzar un $\mathrm{fin}^{5}$. De dos cosas que no pueda disfrutar al tiempo, elige una y rechaza la otra. La acción, por tanto, implica, siempre y a la vez, preferir y renunciar ${ }^{6}(\ldots)$. Ahora bien, también señala que actuar no supone solo hacer, sino también dejar de hacer aquello que podría ser realizado ${ }^{7}(\ldots)$. El hombre, al actuar, aspira a sustituir un estado menos satisfactorio por otro mejor ${ }^{8}$. (Por lo que) es siempre el malestar el incentivo que induce al individuo a actuar (2011: 16-18).

Como resulta evidente, las personas normalmente responden ante incentivos, aprovechando oportunidades para mejorar y debido a esto, los incentivos pueden cambiar el comportamiento de los individuos.

5 El fin último de la acción siempre es la satisfacción de algún deseo del hombre actuante (Mises 2011:24). De acuerdo con Murray Rothbard (2011: 01) la acción humana se define simplemente como comportamiento deliberado (...). Todos los seres humanos actúan en virtud de su existencia y de su naturaleza (...). Añade que toda acción implica el uso de medios escasos para el logro de los fines más valorados y que toda acción es un intento de cambiar un estado de cosas menos satisfactorio por otro más satisfactorio (Rothbard 2011: 17-19).

6 La acción supone decidir y elegir, y por tanto, renunciar.

7 Esta es una buena definición de lo que es la libertad: uno es libre cuando puede hacer o dejar de hacer aquello que podría haberse hecho. Para Hayek la libertad es ausencia de coacción arbitraria (definición negativa).

En otras palabras, la libertad supone una tensión entre aquello que nos predetermina a actuar de una determinada manera (la familia en la que nacimos, la manera en que fuimos educados, la religión que cultivamos, los valores que nos inculcaron, el colegio que estudiamos, la herencia que recibimos, el país en que nacimos) y aquello que por un acto de autodeterminación queremos. Es una tensión que evidentemente cada ser humano debe saber manejar.

Otra acepción es la libertad dentro de la ley, entendida como el derecho, facultad o prerrogativa natural que tiene el ser humano de obrar y no obrar de una manera u otra, según su inteligencia o voluntad dentro los límites impuestos por la ley. Al respecto, nuestra Constitución Política (artículo 2, numeral 24, inciso "a") establece que toda persona tiene derecho a la libertad y seguridad personales. En consecuencia: "Nadie está obligado a hacer lo que la ley no manda, ni impedido de hacer lo que ella no prohíbe". Esta norma tiene su antecedente en la Declaración de los Derechos del Hombre y del Ciudadano (proclamada por la Revolución Francesa en 1789):

Artículo 4: "La libertad consiste en poder hacer todo aquello que no perjudique a otro, el ejercicio de los derechos naturales de cada hombre no tiene otros límites que los que garantizan a los demás miembros de la sociedad el goce de estos mismos derechos. Tales límites sólo pueden ser determinados por la ley".

Artículo 5: "La ley solo tiene derecho a prohibir los actos perjudiciales para la sociedad. Nada que no esté prohibido por la ley puede ser impedido, y nadie puede ser constreñido a hacer algo que esta no ordene".

8 El hombre aspira, no hay nada que garantice que mejore. Nadie lleva a cabo una acción con la intención, sobre todo desde la perspectiva de que para él es un bien, de empeorar. Siempre lo hacemos con la intención de mejorar. 
En ese orden de ideas, el interés de Mises está en el agente que actúa en el mercado (homo agens), y bajo tal premisa, actuar (itercambiar) en el mercado supone la libertad del agente para decidir y elegir; $y$ si el agente decide y elige, por tanto, renuncia a algo (costo de oportunidad $^{9}$ ), por lo menos a no actuar.

Asimismo, es importante precisar que Mises (2011: 11) considera que la Economía es una ciencia teórica que, como tal, se abstiene de establecer normas de conducta. No pretende señalar a los hombres qué metas deben perseguir. Solo quiere averiguar los medios más idóneos para alcanzar aquellos objetivos que otros, los consumidores, predeterminan (si como oferente no ofrecen los bienes y servicios que el consumidor desea, simplemente no los compra); jamás pretende indicar a los hombres los fines que deben aspirar. Las decisiones últimas, la valoración y elección de metas a alcanzar, quedan fuera del ámbito de la ciencia (económica). Nunca dirá a la humanidad qué debe desear, pero sí procurará ilustrarla acerca de cómo debe comportarse si quiere alcanzar determinados fines.

Es indudable que, Mises centra su atención en la Cataláctica, esto es, en el intercambio en el mercado, porque es el intercambio en el mercado, tal como sostenían los clásicos, el que nos permite precisamente ir elevando nuestro nivel de bienestar. Dentro de este marco, la Teoría General del Intercambio en el Mercado implica que los agentes actúan libremente, sean estos oferentes o demandantes $y$, como consecuencia de dicho intercambio, ambos se benefician. Así, la relación de intercambio, tiene una doble dimensión: 1) la económica: transmisión del bien, y 2) la jurídica: transmisión de los derechos de propiedad.

Murray Rothbard ${ }^{10}$ resume (2011: 83-92) los diferentes tipos de acción humana: 1) aislamiento (intercambio autístico) y 2) acción interpersonal. Dentro de esta última contempla: a) acción agresiva (guerra, asesinato, asalto, robo y esclavitud) y b) acción no agresiva (regalo/donación e intercambio voluntario). Obviamente, su interés radica en el análisis de la sociedad no agresiva, particularmente aquella cuya pauta constitutiva es el intercambio voluntario. Para Rothbard, la esencia del intercambio es que se realiza porque ambas personas esperan que las beneficie; si no fuera así, no estarían de acuerdo en llevarlo a cabo. Una condición necesaria para el intercambio es que los dos bienes tengan un orden de valoración distinto en las respectivas escalas de valores de las partes intervinientes (...). La multiplicidad de intercambios voluntarios da forma a una sociedad; da forma también a un patrón de interrelaciones que se conoce como mercado. Una sociedad constituida únicamente por el mercado, se dice que tienen un mercado irrestricto, o mercado libre, que no sufre la interferencia de las acciones violentas. Una sociedad que se fundamenta en los intercambios voluntarios se denomina sociedad contractual, la cual está cimentada en la libre participación, en las relaciones contractuales entre individuos, en contraste con la sociedad hegemónica, que se basa en la acción violenta. Los convenios entre individuos para realizar intercambios reciben el nombre de contratos, y una sociedad basada en convenios voluntarios es una sociedad contractual. Es la sociedad del mercado libre.

Por su parte, Menger $^{11}$ (2013: 240) señala que intercambiamos en la medida en que aquello que recibo, a cambio de lo que doy, valoro más de lo que doy, por lo que intercambiamos por necesidad. En sus palabras " (...) el principio que induce a los hombres al intercambio no es otro sino aquel que guía toda su actividad económica en general, esto es, el deseo de

9 En el fondo, todos los costos son costos de oportunidad. Esto es debido a que siempre que se realiza una elección significa que se ha renunciado a otra alternativa.

10 Murray Rothbard (1926 - 1995) fue un economista, historiador y teórico político estadounidense perteneciente a la Escuela Austríaca de Economía, que contribuyó a definir el moderno liberalismo, el anarcocapitalismo. En su libro "El hombre, la economía y el Estado" señala la fragmentación a que ha llegado la Economía. Parece haberse abandonado la vieja tradición de los Tratados de Economía destinados a la exposición unitaria de los principios de esta ciencia, sustituida por una enorme proliferación de monografías y de estudios sobre aspectos particulares.

11 Carl Menger $(1840$ - 1921) fue un economista austríaco y fundador de la Escuela Austríaca de Economía. Su aporte es la Teoría del Valor en su obra "Principios de Economía Política" (1871). De acuerdo con Menger, el valor de las mercancías depende de la valoración de la persona (el valor es subjetivo), que a su vez depende de su necesidad. No valoramos el satisfactor (el agua), valoramos la satisfacción de la necesidad (quitar la sed).

128/ QVIPURAMAYOC|Vol. 23(44) 2015 
satisfacer sus necesidades de la manera más perfecta posible (...)”.

No hay algo que obligue al ser humano a intercambiar, porque el ser humano lo hace de forma natural, y por tanto, no es necesario una ley. Lo que hacen los agentes económicos de manera natural, sin intervención del gobierno, es intercambiar porque les resulta beneficioso.

En lo esencial, Mises (2011: 313), argumenta que la economía de mercado es un sistema social de división del trabajo basado en la propiedad privada de los medios de producción. Cada uno, dentro de tal orden, actúa según le aconseja su propio interés; todos, sin embargo, satisfacen las necesidades de los demás al atender las propias (...). El mercado impulsa las diversas actividades de la gente por aquellos cauces que mejor permiten satisfacer las necesidades de los demás. En el funcionamiento del mercado no hay compulsión ni coerción (...). El mercado no es un lugar, ni una cosa ni una asociación. El mercado es un proceso puesto en marcha por las actuaciones diversas de los múltiples individuos que entre sí cooperan bajo el régimen de división del trabajo. Ante lo señalado por Mises, debe agregarse que a los austriacos les interesa el enfoque de procesos en lugar de estados finales. Importa como es el proceso del mercado (cómo, comprando y vendiendo, produciendo y consumiendo, los individuos contribuyen al funcionamiento de la sociedad), cómo evoluciona, cómo se desarrolla, cómo se origina. No se preocupan por estados finales como los economistas neoclásicos, que se enfocan en los equilibrios (cómo hacer para llegar al equilibrio). Contrario a ellos, los austriacos se interesan en analizar cómo funciona el proceso que tiende al equilibrio. Es más, afirman que es poco probable pensar que el mercado siempre está en equilibrio. También, reconocen que las valoraciones que se puedan tener en función de resultados son subjetivas y nadie más que cada persona la puede conocer.
En suma, el intercambio es la actividad económica central, en función a la cual giran las demás, ya que la mayoría de agentes económicos produce para el mercado y la mayoría de los consumidores satisfacen sus necesidades comprando en el mercado. No obstante, para Mises (2011: 765) ni la Praxeología en general ni la Economía y la Cataláctica en particular proclaman ni suponen que el hombre es libre en el sentido metafísico asignado al término libertad. El individuo está incondicionalmente sometido a las condiciones naturales de su ambiente (...). Es precisamente la escasez de los medios naturales lo que obliga al hombre a actuar.

\section{ORDEN ESPONTÁNEO DEL MERCADO}

De acuerdo con Hayek ${ }^{12}$ (2014: 58) por orden ${ }^{13}$, entendemos una situación en la que una multiplicidad de elementos de diverso género se halla en tal relación unos con otros, que del conocimiento de alguna parte temporal o espacial del conjunto podemos aprender a formarnos expectativas sobre otras partes del mismo conjunto, o, por lo menos, expectativas con una buena posibilidad de resultar acertadas. Es claro que en este sentido toda sociedad debe disponer de algún tipo de orden, y que con frecuencia ese orden existirá sin que haya sido deliberadamente creado $^{14}$.

Desde tal perspectiva, Hayek (2014: 61-2) precisa que (...) tales órdenes (construidos o taxis) son órdenes relativamente simples (...); suelen ser concretos $(. .$.$) que su existencia puede percibirse$ intuitivamente por simple observación; $y$, finalmente, al haber sido construidos deliberadamente, sirven invariablemente a los fines de su creador. Ninguna de estas características pertenece necesariamente a un orden espontáneo o cosmos. Su grado de complejidad no está limitado a lo que una mente humana pueda dominar. Su existencia no necesita manifestarse a nuestros sentidos, sino que puede basarse simplemente en relaciones abstractas que nosotros solo

12 Friedrich A. Von Hayek (Viena 1899 - Friburgo de Brisgovia 1992) considerado el inspirador de la Escuela de Chicago y maestro reconocido por la Escuela Austriaca, fue uno de los mayores críticos de la economía planificada y socialista. Recibió el Premio Nobel de Economía en 1974, junto con Gunnar Myrdal por su trabajo pionero en la teoría del dinero y las fluctuaciones económicas, y por sus penetrantes análisis de la interdependencia de los fenómenos económicos, sociales e institucionales.

13 Para Hayek el término orden puede ser sistema, estructura o modelo.

14 Las normas de conducta que el hombre de leyes estudia están al servicio de un orden cuya naturaleza el jurista ignora en gran medida; y que este orden lo estudia principalmente el economista, que a su vez ignora igualmente el carácter de las normas de conducta en que descansa el orden en cuestión (Hayek 2014: 19). 
podemos reconstruir mentalmente. $Y$ al no haber sido construidos deliberadamente, no se puede legítimamente decir que tengan un objetivo particular (...).

La idea primordial de Hayek es que el orden espontáneo es el sistema que se autogenera de manera evolutiva por las acciones humanas no intencionadas, es un orden que no ha sido creado artificialmente (deliberadamente) a través del diseño humano, por tanto, no es susceptible de conocimiento completo por parte de los individuos. Argumenta que el orden espontáneo se descubre o se desarrolla a través de un proceso de prueba y error, en el que los grupos sociales irán adaptando o reajustando sus acciones individuales sobre la base de los nuevos elementos que van apareciendo (ya sean conocimientos, valores, costumbres, normas, precios, etc.), de tal manera que solo aquellos elementos que faciliten el intercambio o la supervivencia de dichos grupos tenderán a prevalecer sobre aquellos elementos menos eficaces. Es más, los grupos sociales que opten por los elementos menos eficaces se verán obligados a elegir entre imitar a otros grupos o simplemente desaparecer. De este modo, los grupos sociales irán renunciando o dejando de lado todo aquello que no sea beneficioso o de interés para la sociedad.

A continuación, se puede apreciar las principales diferencias entre el orden espontáneo, dentro del cual se encuentra el mercado (que es producto del racionalismo evolutivo ${ }^{15}$ ), y el orden construido que es el resultado del diseño humano (racionalismo constructivista $\left.{ }^{16}\right)$. Sobre el particular, resulta muy relevante la distinción que realiza Hayek al referirse al racionalismo (2014: 51) "si racionalismo significa tratar de buscar la mayor eficacia posible de la razón, también yo soy racionalista. Si, en cambio, con este término se pretende indicar que la razón consciente debe determinar toda acción particular, yo no soy racionalista, y considero ese racionalismo muy poco racional".

\section{Tabla No 01}

Dos fuentes de orden: espontáneo (evolutivo) y construido (artificial)

\begin{tabular}{|l|l|}
\hline \multicolumn{1}{|c|}{ Orden espontáneo } & \multicolumn{1}{c|}{ Orden construido } \\
\hline Orden que se autogenera o endógeno & Orden que se construye o exógeno \\
\hline Formado por la evolución & Creado artificialmente a través del diseño humano \\
\hline $\begin{array}{l}\text { Proviene de acciones humanas no intencionadas } \\
\text { encaminadas a otros fines }\end{array}$ & Proviene de planes intencionados (deliberados) \\
\hline $\begin{array}{l}\text { Carece de finalidad concreta (cuyo contenido particu- } \\
\text { lar no es conocido o previsto) }\end{array}$ & Tiene fines concretos (mandatos específicos) \\
\hline $\begin{array}{l}\text { Sustentado en el racionalismo evocionista (reconoce } \\
\text { la abstracción como único instrumento con el que } \\
\text { nuestra mente puede tratar una realidad cuya plena } \\
\text { comprensión se le escapa) }\end{array}$ & $\begin{array}{l}\text { Sustentado en el racionalismo constructivista (no re- } \\
\text { conoce los conceptos abstractos son un medio para } \\
\text { vencer la complejidad de lo concreto) }\end{array}$ \\
\hline $\begin{array}{l}\text { Instituciones de mayor importancia: la sociedad, la } \\
\text { costumbre, la moral, el lenguaje, la moneda, el mer- } \\
\text { cado, la competencia, el liberalismo, la estructura de } \\
\text { capital de una economía por evolución }\end{array}$ & $\begin{array}{l}\text { Concibe todas las instituciones como resultado de pla- } \\
\text { nes deliberados: la familia, el gobierno, una organiza- } \\
\text { ción, una empresa, el ejército y la legislación }\end{array}$ \\
\hline $\begin{array}{l}\text { Griegos: utilizaron el término "cosmos" para el orden } \\
\text { formado por evolución }\end{array}$ & $\begin{array}{l}\text { Griegos: utilizaron el término "taxis" para el orden } \\
\text { creado artificialmente }\end{array}$ \\
\hline
\end{tabular}

Fuente: Elaboración propia.

\footnotetext{
15 El racionalismo evolucionista se basa en una interpretación evolucionista de todos los fenómenos de la cultura y del espíritu y en una comprensión de los límites de los poderes de la razón humana. Respetuosa de la tradición y reconoce que todo conocimiento y toda civilización se apoya en la tradición.

16 El racionalismo constructivista es la concepción que conduce al tratamiento de todo fenómeno cultural como el producto de un plan deliberado y en la creencia de que es posible reconstruir todas las instituciones desarrolladas de acuerdo con un plan preconcebido.
} 
La principal razón es que estos órdenes, como el mercado, no se imponen a nuestros sentidos, sino que deben ser descubiertos por nuestra inteligencia. (...) el orden de mercado en particular asegurará sólo con cierta probabilidad la vigencia de las relaciones esperadas; en todo caso, representa el único modo en que muchas actividades, basadas en el conocimiento disperso de muchos sujetos, pueden integrarse efectivamente en un único orden (Hayek 2014: 61-6).

\section{Diagrama No 02}

Mercado como orden espontáneo

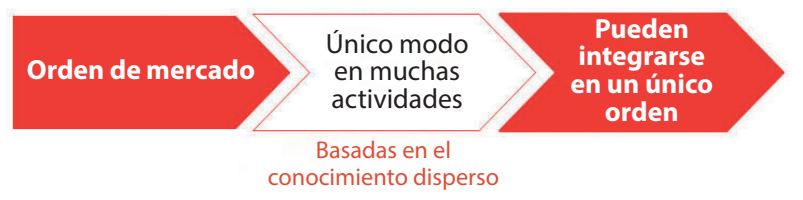

Fuente: Elaboración propia.

En ese entender, para Hayek la división del conocimiento es tan importante como la división del trabajo $^{17}$, pero menos estudiado. Lo que intercambiamos en el mercado es conocimiento y luego productos, de modo que la cooperación es fundamental para el ser humano. Efectivamente, dos personas, un oferente y un demandante que logran intercambiar (actuar) terminan cooperando entre ellos y, el resultado de esa cooperación, es que después de realizar el intercambio, ambas partes salen ganando porque mejora el bienestar de ambos. Para entender esto último, debemos comprender que cada vez que el ser humano actúa, lo hace con la intención de mejorar su condición. En el caso específico del intercambio, mejorar la condición de las partes que intervienen en la transacción, supone que cada uno valora más lo que recibe de lo que $\mathrm{da}^{18}$.

Para Jesús Huerta (2014: 75) el anarcocapitalismo es la representación más pura del orden espontáneo del mercado en el que todos los servicios, incluyendo los de definición del derecho, justicia y orden público, son proporcionados a través de un proceso exclusivamente voluntario de cooperación social que se convierte así en el objeto central de investigación de la Ciencia Económica moderna (...), el sistema propuesto elimina los incentivos corruptores del ser humano que genera el Estado, impulsando por el contrario los comportamientos humanos más morales y responsables, e impidiendo el surgimiento de ninguna agencia monopolista (Estado) que legitime el uso sistemático de la violencia y la explotación por parte de unos grupos sociales.

Un aspecto importante con relación al orden construido es lo afirmado por Adam Smith ${ }^{19}$ (2013: 407) en el sentido que el hombre doctrinario, en cambio, se da ínfulas de muy sabio y está casi siempre tan fascinado con la supuesta belleza de su proyecto político ideal que no soporta la más mínima desviación de ninguna parte del mismo (...). Se imagina que puede organizar a los diferentes miembros de una Gran Sociedad con la misma desenvoltura con que dispone las piezas en un tablero de ajedrez. No percibe que las piezas del ajedrez carecen de ningún otro principio motriz salvo el que les imprime la mano, $y$ que en el vasto tablero de la sociedad humana cada pieza posee un principio motriz propio, totalmente independiente del que la legislación arbitrariamente elija imponerle. Si ambos principios coinciden y

17 La división del trabajo divide a los agentes económicos en 2 grandes grupos: ofertantes y demandantes. En tal sentido, por el simple hecho de encontrarnos en un supermercado con la intención de comprar algo, supone que aquello que deseamos comprar no lo producimos, ahí está la división del trabajo. Para Krugman y Wells (2013: 12) la clave para tener un mejor nivel de vida es el comercio, en el que los individuos se reparten las tareas y cada uno ofrece un bien o un servicio que otros demandan, a cambio de bienes y servicios que desea (...). Las ganancias del comercio se derivan de la división del trabajo que los economistas denominan especialización, una situación en la que cada individuo se dedica a una tarea diferente, ocupándose de aquellas tareas que sabe hacer mejor.

18 El valor es la significación que un bien adquiere para nosotros por el hecho de que somos conscientes de que dependemos de su posesión para la satisfacción de alguna de nuestras necesidades, de tal suerte que tendríamos que renunciar a esta satisfacción si no dispusiéramos de dicho bien (...). Para que un bien adquiera valor, debe asegurarnos la satisfacción de necesidades que no lo estarían si no dispusiéramos de dicho bien (Menger 2013: 288).

19 Adam Smith (1725-1790) fue economista escocés a quien se le considera como el padre de la Ciencia Económica y fundador de la Escuela Clásica. Gran amigo personal de David Hume. En Francia trabó conocimiento personal con Quesnay y otros fisiócratas, que le influyeron notablemente y le indujeron a poner manos a su obra "Investigación sobre la naturaleza y las causas de la riqueza de las naciones", cuya redacción le llevó doce años (publicada en 1776). 
actúan en el mismo sentido, el juego de la sociedad humana proseguirá sosegada y armoniosamente y muy probablemente será feliz y próspero. Si son opuestos o distintos, el juego será lastimoso y la sociedad padecerá siempre el máximo grado de desorden.

La explicación de Smith resulta sumamente valiosa si de lo que se trata es conservar una sociedad libre, porque asevera categóricamente que el hombre constructivista -de manera errónea- se atribuye la sabiduría de poder organizar a los miembros de una Gran Sociedad y elevar así el nivel de bienestar, para lo cual crea mundos utópicos (paraísos terrenales) que solamente prevalecen en la mente de quien la concibe (orden construido por el diseño humano). Smith diferencia los principios motriz de las piezas de un tablero de ajedrez y las piezas del vasto tablero de la sociedad humana. En efecto, sostiene que a las piezas de un tablero de ajedrez si alguien no las mueve, no se mueven (carecen de principio motriz), hay que moverlas con la mano; pero el vasto tablero de la sociedad humana, el ser humano no es alguien a quien otro pueda moverlo a su voluntad (cada pieza posee principio motriz propio). Inclusive, el hombre constructivista podrá intentarlo, pero el único resultado será el desorden.

Se debe tener en cuenta que la Gran Sociedad surgió del descubrimiento de que los hombres podían vivir juntos en paz y beneficiándose unos a otros sin tener que ponerse de acuerdo sobre los fines específicos que individualmente persiguen (...). El paso decisivo que hizo posible esta pacífica colaboración en ausencia de fines comunes concretos fue la adopción del trueque o intercambio. Se conoció simplemente que personas distintas hacía usos diversos de las mismas cosas y que a menudo ambas salían ganando, obteniendo el bien que el otro poseía y dando a cambio lo que el otro necesitaba. Lo único que se precisaba para que así sucedieran las cosas era reconocer ciertas normas ${ }^{20}$ que determinaran qué es lo que pertenece a cada uno y cómo esta propiedad puede transferirse mediante consentimiento. No se necesitaba que las partes se pusieran de acuerdo sobre los fines de la transacción (Hayek 2014: 311).

Ahora bien, lo que Hayek rechaza es considerar al orden espontáneo como si fuera un orden construido, porque no se puede concebir a la sociedad o el mercado (que no tienen fines) como cualquier organización o empresa (que sí tienen fines). Sin embargo, muchos consideran reprobable que la Gran Sociedad no tenga fines comunes concretos. En buena cuenta es necesario enfatizar que para Hayek la Sociedad debe estar ligada tan sólo en los medios pero no en los fines y es precisamente la ausencia de fines comunes prescritos -como pretenden los constructivistas-lo que hace que sea posible una sociedad de hombres libres.

En efecto, el juego de la catalaxia ${ }^{21}$ es un juego generador de riqueza (...) un juego que lleva a un aumento del flujo de los bienes, y de las perspectivas de todos los participantes de satisfacer sus propias necesidades, pero que conserva el carácter de juego en el sentido que al término da el Oxford English Dictionary: "una competición que se juega según reglas, cuyo resultado depende de la habilidad, fuerza o suerte superiores" (...). El productor no fabrica zapatos porque sabe que Pérez los necesita. Los produce porque sabe que decenas de comerciantes comprarán ciertas cantidades a precios distintos, sabiendo a su vez que millares de Pérez, desconocidos para productor, quieren comprarlos. La suerte es un elemento inseparable del funcionamiento del mercado, al igual que la habilidad (Hayek 2014: 319).

20 De acuerdo con Hayek, las normas fueron elaboradas en forma espontánea mucho antes de que la gente alcanzara a comprender conceptos, abstracción como ley, Derecho, justicia o tribunales, ya estaba respetando ciertas normas, porque si no lo hacía, tendría problemas. Afirma (2014: 19) que las normas de conducta que el hombre de leyes estudia están al servicio de un orden cuya naturaleza el jurista ignora en gran medida; y que este orden lo estudia principalmente el economista, que a su vez ignora igualmente el carácter de las normas de conducta en que descansa el orden en cuestión.

21 El término "catalaxia" deriva del término griego katallattein que, significativamente, denotaba, no sólo "intercambiar", sino también "admitir en la comunidad" y "convertirse de enemigos en amigos". De donde el adjetivo "cataláctico", que denota, sustituyendo a "económico", los fenómenos de que trata la ciencia de la catalaxia (...). Catalaxia designa el orden generado por la recíproca adecuación de las distintas economías dentro de un mercado. Una catalaxia es, pues, un tipo especial de orden espontáneo producido por el mercado a través de individuos que actúan según las normas del derecho de propiedad, el contrato y exclusión del fraude (Hayek 2014: 310-11). 
Diagrama No 03

Implicancias del juego de la catalaxia

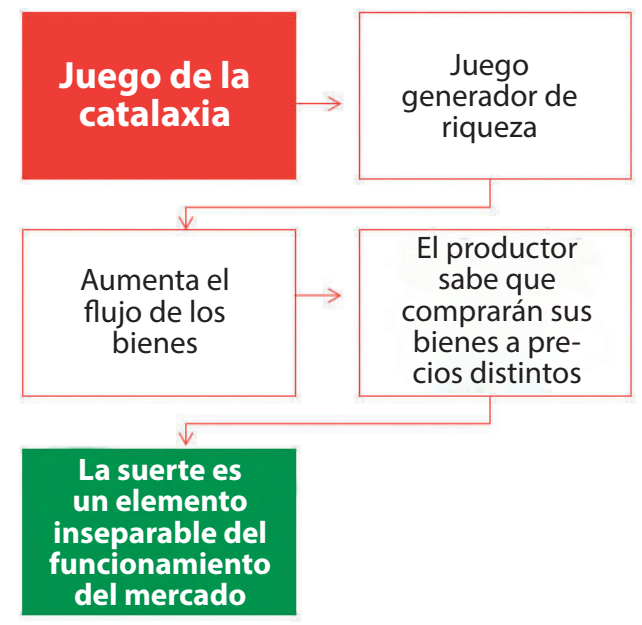

Fuente: Elaboración propia.

\section{PRINCIPIOS GENERALES DE UNA SOCIEDAD LIBRE}

Una sociedad libre en la que todos los ciudadanos hacen uso de su conocimiento para sus fines particulares, limitada únicamente por reglas de recto comportamiento ${ }^{22}$, solo puede conservarse si los gobiernos de turno se encuentran limitados en el ejercicio coactivo del poder por principios generales a los que la Gran Sociedad ha sometido, principios que constituyen los criterios informadores y orientadores del orden espontáneo.

No obstante, tras la experiencia de los últimos treinta años, posiblemente no haya necesidad alguna de subrayar que sin principios vamos a la deriva. La actitud pragmática dominante en ese periodo, lejos de aumentar nuestro control sobre los desarrollos de los hechos sociales, nos ha llevado, en cambio, a una situación que nadie quería (...). El problema, ahora no es si debe haber principios que nos guíen, sino más bien, si aún existe un conjunto de principios que puedan aplicarse en general (Hayek 2009: 48-9).
De esta manera, los principios generales de una sociedad libre se sustentan en el liberalismo evolucionista ${ }^{23}$ que proviene del descubrimiento de un orden espontáneo, un orden que hizo posible la utilización del conocimiento y aptitud de todos los miembros de la sociedad en un grado mucho mayor del que sería posible en cualquier orden creado por una dirección central.

Sin perjuicio de lo expresado en el párrafo precedente, el liberalismo evolucionista reconoce que hay, determinados servicios que por diversos motivos las fuerzas espontáneas del mercado no pueden brindar o en todo caso no pueden ofrecerlo en forma adecuada, y por tanto, es conveniente poner a disposición del gobierno ${ }^{24}$ de turno los recursos necesarios con los cuales se pueda prestar tales servicios en beneficio de la población en general.

En palabras de Hayek (2012: 252) los principios básicos de una sociedad liberal pueden resumirse diciendo que en una sociedad de esta índole todas las funciones coercitivas del gobierno deben inspirarse en la importancia superior de los que llamo las tres grandes negaciones: paz, justicia y libertad. Para lograrlas se requiere que el gobierno, en sus funciones coercitivas, se limite a la ejecución de prohibiciones (establecidas como reglas abstractas) tales que puedan aplicarse igualmente a todos y que se limite a exigir que, según las mismas reglas uniformes, todos participen de los costos de los demás y que pueda tomar la decisión de ofrecer servicios a los ciudadanos en forma no coercitiva, con los medios materiales y las personas que para ese objeto le hayan sido puestas a su disposición.

En esa línea, es necesario reivindicar aquellos principios de una sociedad libre, referidos a la tradición de la libertad individual, la justicia y el gobierno limitado (véase diagrama), con la finalidad de contribuir a fortalecer el orden espontáneo del

\footnotetext{
22 Las reglas de recto comportamiento son normas generales y abstractas, universalmente aplicables, que no tienden a un fin y que contribuyen a la formación de un orden espontáneo. Válidas para un número indeterminado de casos y para un período muy largo, y son de carácter negativo (prohibitivo). Se aprenden imitando acciones particulares: una persona adquiere la capacidad de obrar en otros casos similares sobre la base de los mismos principios.

23 El liberalismo evolucionista (Inglaterra) debe distinguirse de otro liberalismo, de tradición continental europea, que comenzó con un intento de imitar la primera tradición, lo interpretó movido por el espíritu de un constructivismo racionalista prevaleciente en Francia (liberalismo constructivista), llegó a sostener el ideal de los poderes ilimitados de la mayoría, en lugar de abogar por limitaciones a los poderes del gobierno.

24 Lo que actúa o persigue una determinada política es siempre, la organización del gobierno; y no el Estado.
} 
mercado, el cual producto del ensayo y error, permite que muchas actividades de los millones de agentes económicos, basadas en el conocimiento disperso, pueden integrarse efectivamente en un único orden, el del mercado, que es fruto de las múltiples acciones humanas que se dan evolutivamente, los cuales terminan elevando nuestro nivel de bienestar.

\section{Diagrama No 04}

Principios generales de una sociedad libre

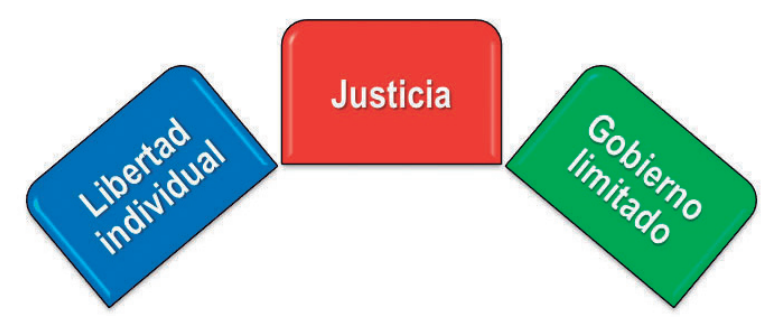

Fuente: Elaboración propia.

En definitiva, para que prevalezcan estos tres principios, se requiere que el gobierno, en sus funciones coercitivas, se limite a la ejecución de prohibiciones (establecidas como reglas abstractas) de tal manera que puedan aplicarse a todos por igual. De modo que, ninguna sociedad libre puede soslayar la importancia superior de tales principios.

En esa orientación, uno de los axiomas ${ }^{25}$ de la tradición de la libertad es que la coacción ${ }^{26}$ solo es admisible cuando es imprescindible para fomentar el bienestar general o el bien público ${ }^{27}$ (véase diagrama). Sin embargo, aunque está claro que el énfasis en el carácter general común o público de los asuntos que son objeto legítimo del ejercicio del poder político intenta evitar que se pongan al servicio de intereses particulares, la vaguedad de los distintos términos empleados ha permitido declarar interés general casi cualquier interés y obligar a muchos a perseguir fines por los que no están en absoluto interesados (Hayek 2014: 187).

\section{Diagrama No 05}

Axioma de la libertad

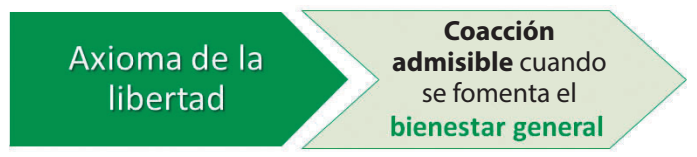

Fuente: Elaboración propia.

Si bien, la coacción es admisible cuando se fomenta el bienestar general, la coacción arbitraria por parte del gobierno debe ser reducida al mínimo, para que las personas procedan acorde a sus fines y planes de vida. Para Hayek (1998: 32) el estado en que un hombre no se halla sujeto a coacción derivada de la voluntad arbitraria de otro o de otros se distingue a menudo como libertad "individual" o "personal".

El gobierno no debe pretender alcanzar fines particulares porque eso implicaría concebir a la Economía como una ciencia prescriptiva, y no descriptiva. Cuando el gobierno procura planear, conducir, coordinar y orientar las actividades económicas de un país lo que está buscando es lograr aquellos fines específicos. En ese entender, el cuestionamiento al hecho de que el gobierno planee, conduzca, coordine y oriente las actividades económicas sería: ¿Por qué el gobierno tendría que decirnos a los ciudadanos en qué se debe trabajar, cómo se debe trabajar, qué se debe consumir, en qué cantidades, etc.?. Bajo tal premisa, el gobierno no puede ni debe establecer fines particulares ni planes de vida para la Gran Sociedad.

Desde luego (tal como se aprecia en el siguiente diagrama), el principio más general en el que se basa un sistema individualista ${ }^{28}$ consiste en servirse de la

25 Los axiomas son afirmaciones que son tan evidentes que no necesitan demostrarse, ni lógica ni empíricamente.

26 Según el Diccionario de la Lengua Española, coacción es el poder legítimo del derecho para imponer su cumplimiento o prevalecer sobre su infracción.

27 El más importante de los bienes públicos que se le exige al poder político no es por tanto la satisfacción directa de ninguna necesidad particular, sino asegurar las condiciones en las que individuos y grupos menores tengan oportunidades favorables de atender mutuamente a sus respectivas necesidades (Hayek 2014: 188).

28 Ningún término político ha sido tan maltratado como el término “individualismo". No sólo sus adversarios lo han distorsionado hasta el punto de convertirlo en una caricatura irreconocible, sino que también se ha empleado para describir diferentes actitudes hacia la sociedad que entre ellas tienen tan poco en común como con sus opuestas (...); y además el término se caracteriza por el hecho de que la palabra "socialismo" se acuñó expresamente en oposición al individualismo (Hayek 2009: 49-50). 
aceptación universal de principios generales como medios para crear orden en los asuntos sociales (...). Nuestra sumisión a los principios generales es necesaria porque no podemos ser guiados en nuestras acciones prácticas por una valoración y un conocimiento completos de todas las consecuencias. Mientras los hombres no sean omnipresentes, el único modo en que se puede dar libertad al individuo es a través de reglas generales que delimiten la esfera de sus decisiones. No puede haber libertad si el gobierno no se limita a tipos de acción particulares, sino que puede usar sus poderes de cualquier modo que sirva para alcanzar fines particulares (Hayek 2009: 71).

\section{Diagrama No 06}

Principio más general en que se basa un sistema individualista

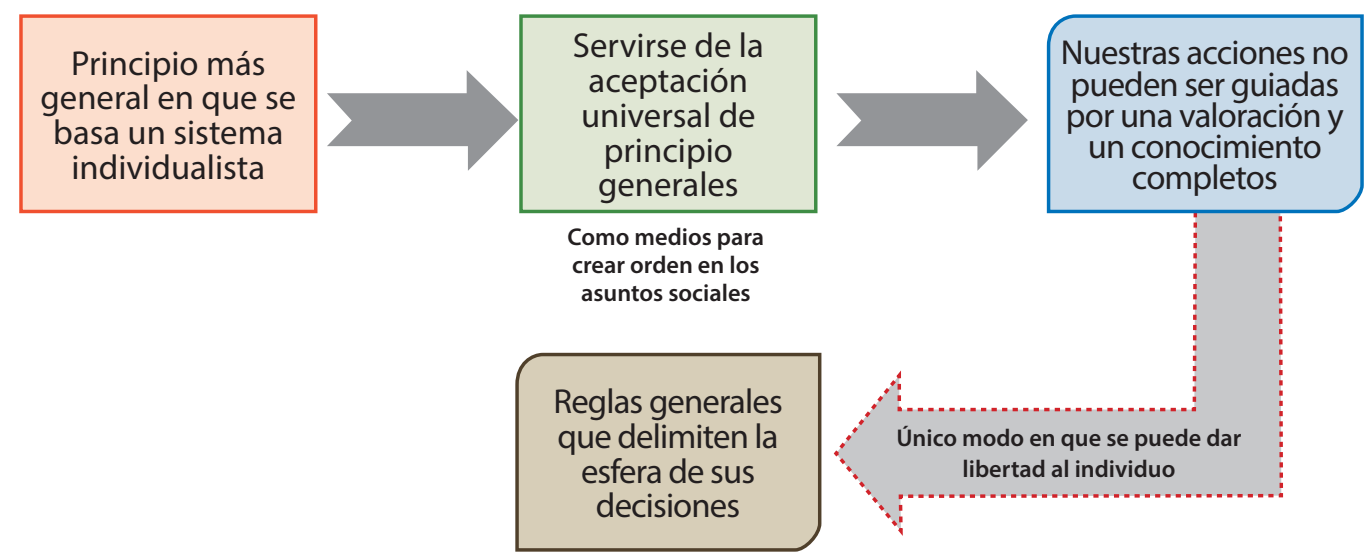

Fuente: Elaboración propia.

Para Hayek (2014:261-2) el concepto de justicia entendido como fundamento y limitación indispensable de cualquier ley, quisiera ahora criticar el abuso de este término, que amenaza con destruir el concepto de ley como baluarte de la libertad individual (...). La "justicia social" (o, a veces, justicia "económica") se vio como atributo que debían poseer las "acciones" de la sociedad, o el "tratamiento" que los individuos olos grupos recibían de la misma (...). Los resultados del orden espontáneo del mercado han sido interpretados como si estuvieran dirigidos por una mente racional (...). Esta concepción de la justicia "social" es, pues, una consecuencia directa de aquel antropomorfismo o personificación con el que el pensamiento primitivo trata de explicar todos los procesos de auto-ordenación ${ }^{29}$.
Si se quiere obtener una "justicia social", es necesario pedir a los individuos que obedezcan no solo a normas generales, sino también a específicas demandas dirigidas sólo a ellos (...). No puede haber ningún conjunto de tales normas o principios en virtud de los cuales los individuos puedan dirigir su propia conducta, dentro de una Gran Sociedad, de tal suerte que el efecto conjunto de sus actividades sea una distribución de beneficios que pudiera calificarse de materialmente justa (Hayek 2014: 287).

Ninguna acción humana particular está plenamente determinada sin que haya un propósito concreto por lograr. Los hombres libres, no deben quedar sujetos a reglas que les señalen lo que positivamente deben hacer, sino únicamente a reglas que les indiquen lo que no deben hacer. No obstante, hay

29 No solo en el caso de "justicia social", sino también "democracia social”, "economía social de mercado", o el "estado social de derecho" son expresiones tales que, si justicia, democracia, economía de mercado o Rechtsstaat tienen, tomadas aisladamente un significado claro, el añadido del adjetivo "social" hace que se les pueda dar el significado que más guste. Esta palabra se ha convertido en una de las fuentes principales de la confusión del lenguaje político y probablemente ya no se podrá emplearla útilmente. Parece que no tendrá fin la violencia que se seguirá haciendo al lenguaje con tal de fomentar un determinado ideal: el ejemplo de "justicia social" ha hecho nacer recientemente la expresión “justicia global” (Hayek 2014: 281). 
algunas raras excepciones a esto, como las acciones para salvar o proteger la vida, prevenir catástrofes y otras similares, casos en los cuales o bien las reglas de la justicia exigen efectivamente de alguna acción positiva (...). La cláusula fundamental de este modelo de constitución debería afirmar que en tiempos normales, y al margen de ciertas emergencias claramente definidas, solo podría impedirse a los hombres que hicieran lo que quisieran u obligarles a ejecutar determinadas acciones, en consonancia con las normas reconocidas de recta conducta, concebidas para definir y proteger el ámbito de la libertad individual. La cláusula fundamental no definiría las funciones de gobierno sino solo los límites de sus poderes coactivos (véase diagrama). Aunque restrinja los medios que el gobierno puede emplear para prestar servicios a los ciudadanos, no pondría límites directos al contenido de esos servicios (Hayek 2014: 477).

\section{Diagrama No 07}

Cláusula fundamental de un modelo de Constitución

\begin{tabular}{|c|c|}
\hline $\begin{array}{c}\text { Cláusula } \\
\text { fundamental }\end{array}$ & $\rightarrow \begin{array}{c}\text { Limites de los } \\
\text { poderes coactivos }\end{array}$ \\
\hline
\end{tabular}

Fuente: Elaboración propia.

Es importante que la constitución establezca los límites a los poderes gubernamentales. Hayek al referirse a la experiencia británica, argumentaba cómo una constitución que define y separa los diferentes poderes limita necesariamente los poderes de cualquier autoridad (Hayek 1998: 241).

Adicionalmente, se debe destacar lo señalado por Bastiat ${ }^{30}$ (2014: 102-3) cuando se plantea la interrogante: ¿Cuáles son los pueblos más felices, los más morales, los más pacíficos?. Asegura que aquellos donde la ley interviene menos en la actividad privada; donde el gobierno se hace sentir menos; donde la individualidad tiene el mayor recorrido $y$ la opinión pública la mayor influencia; donde los procesos administrativos son menos numerosos y menos complicados; los impuestos menos pesados y menos desiguales; los descontentos populares menos exaltados y menos justificables; donde la responsabilidad de individuos y clases es más efectiva, y donde, en consecuencia, si las costumbres no son perfectas, tienden irresistiblemente a corregirse; donde las transacciones, los acuerdos y las asociaciones son menos intervenidas; donde el trabajo, capital y población sufren menores desplazamientos artificiales; donde la humanidad obedece más a su propia inclinación; donde el pensamiento de Dios prevalece más sobre las invenciones de los hombres; aquellos, en una palabra, que más se acercan a esta solución: Dentro de los límites del derecho, todo por la libre y perfectible espontaneidad del hombre; nada por la ley o la fuerza salvo la justicia universal.

El error fatal de los liberales clásicos radica en no haberse dado cuenta de que el programa del ideario liberal es teóricamente imposible pues incorpora dentro de sí mismo la semilla de su propia destrucción, precisamente en la medida en que considera necesaria y acepta la existencia de un Estado (aunque sea mínimo) entendido como la agencia monopolista de la coacción institucional (Huerta 2014: 66).

Una sociedad libre, donde prima la libertad individual, promueve el emprendimiento y la creatividad. Siendo así, las normas de recta conducta sólo pueden originar oportunidades para adquirir determinados derechos. Tal como sostienen Milton y Rose Friedman (1980: 193) las medidas estatales que apoyan la igualdad personal o la de oportunidades aumentan la libertad; las medidas estatales que pretenden lograr "partes equitativas para todos" reducen la libertad (...). "Equidad" no es un concepto objetivamente determinado desde el momento en que depende de la identidad. La "equidad", como las "necesidades" depende del espectador. Si todos han de tener "partes equitativas", alguien o algún grupo de personas debe decidir qué partes son equitativas, y deben ser capaces de imponer sus decisiones a los demás quitando

30 Fréderic Bastiat (1801-1850) fue un escritor, legislador y economista francés al que se considera uno de los mejores divulgadores del liberalismo de la historia. Fue parte de la Escuela liberal francesa y paladín de la propiedad privada, el libre mercado y el gobierno limitado. Su carrera pública como economista inició en 1844. Su temprana muerte fue debida a la tuberculosis, que probablemente se contagió durante sus numerosos viajes por toda Francia para promover sus ideas liberales. Su enfermedad le impidió primero seguir con su actividad pública, especialmente en la asamblea legislativa para la que fue elegido en 1848 y 1849.

136/ QVIPURAMAYOC | Vol. 23(44) 2015 
a los que tienen más que lo equitativo, dando a los que tienen menos.

Por lo tanto, existe una enorme diferencia entre tratar igual a las personas $y$ tratar de hacerlas iguales. Lo primero es la condición esencial de una sociedad libre que se sustenta en la libertad individual, en cambio lo segundo, constituye una distorsión de la igualdad y consiguientemente de la libertad individual. Tal como asevera Hayek la única igualdad que es posible entre seres que somos totalmente desiguales es la igualdad de trato: igualdad ante la Ley. De tal manera, que entre seres completamente desiguales, el ideal es que no haya privilegios ni exclusiones en la sociedad, sino que, todos seamos tratados por igual.

Una sociedad que anteponga a la libertad la igualdad (en el sentido de los resultados) acabará sin una ni otra. El uso de la fuerza para lograr la igualdad destruirá la libertad, y la fuerza, introducida con buenas intenciones, acabará en manos de personas que la emplearán en pro de sus propios intereses. Por otra parte, una sociedad que ponga en primer lugar la libertad acabará teniendo, como afortunados subproductos, mayor libertad y mayor igualdad. La mayor igualdad, aunque sea un subproducto de la libertad, no es un accidente. Una sociedad libre desata las energías y capacidades de las personas en busca de sus propios objetivos (...) pero mientras perdure la libertad, ésta impide que tales posiciones privilegiadas se institucionalicen, y dichos individuos están obligados a recibir continuos ataques de otras personas capaces y ambiciosas. Libertad significa diversidad, pero también movilidad (Friedman 1980: 209).

\section{Diagrama $\mathrm{N}^{\circ} 08$}

Mayor libertad implica mayor igualdad

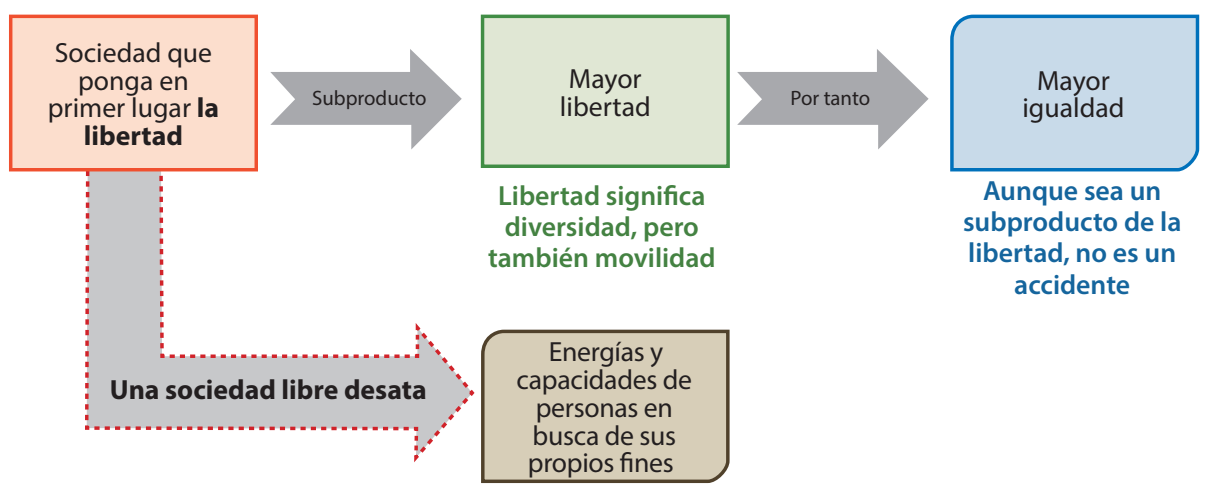

Fuente: Elaboración propia.

\section{CONCLUSIONES}

1. El objeto de estudio de la Praxeología es la acción humana. El fin de la acción humana es mejorar. En virtud de ello, un principio básico en el análisis económico es que las personas normalmente responden ante incentivos, aprovechando las oportunidades para mejorar. Como tal, actuar supone hacer o no hacer lo que podría haberse hecho. Consecuentemente, actuar supone libertad, debido a que una persona es libre cuando puede hacer o dejar de hacer algo. Asimismo, el ser humano cuando actúa siempre implica renunciar a algo, que en estricto es su costo de oportunidad, lo cual se explica porque siempre que las personas efectúan una elección necesariamente renuncian a otra alternativa.

2. La Cataláctica es la parte más importante de la ciencia económica, y esta a su vez, forma parte de una ciencia más amplia, que es la Praxeología. De modo que, para los austriacos la Economía es una ciencia descriptiva, que describe ciertos fenómenos, en particular el fenómeno cataláctico. Se interesan por responder las siguientes interrogantes: ¿Qué es un mercado?, ¿Qué elementos forman el mercado?, ¿Cómo actúan los diversos 
agentes en el mercado?, ¿Qué se necesita para que el mercado funcione bien?. De ello, se colige que buscan describir o tratan de entender una realidad concreta. Por tanto, la Economía no es una ciencia prescriptiva, que determine (prescriba) lo que se deba hacer.

3. El orden espontáneo del mercado se fundamenta en los principios generales de una sociedad libre: libertad individual, justicia y gobierno limitado. Permite que muchas de las actividades realizadas por las personas, basadas en el conocimiento disperso, pueden integrarse en un único orden, el del mercado; que a su vez, es fruto de las múltiples acciones humanas no intencionadas encaminadas a otros fines, las cuales elevan nuestro nivel de bienestar como consencuencia del intercambio. En este marco, no se puede considerar al orden espontáneo del mercado como si fuera un orden construido (creado por diseño humano). Sin embargo, con bastante frecuencia, los gobiernos intervienen (interfieren) los mercados en forma desmesurada creando ciertos privilegios y destruyendo así el orden espontáneo. De ahí que, resulta relevante que los gobiernos de turno no distorsionen el orden espontáneo del mercado, pretendiendo alcanzar fines concretos.

\section{REFERENCIAS BIBLIOGRÁFICAS}

1. BASTIAT, F. (2014) La Ley. Publicada originalmente en 1850. Impreso en Alemania.

2. FRIEDMAN, M. - FRIEDMAN R. (1980) Libertad de elegir. España Ediciones Grijalbo S.A.

3. HAYEK, F. (2014) Derecholegislación y libertad. Segunda edición. Edición original en ingles Vol.
1 (1973), Vol. 2 (1976) y Vol. 3 (1979). España. Unión Editorial S.A.

4. HAYEK, F. (2012) Estudios de filosofía, política y economía. Segunda edición (edición original en ingles 1967). España. Unión Editorial S.A.

5. HAYEK, F. (2009) Individualismo: el verdadero y el falso. Edición original en ingles 1949. España. Unión Editorial S.A.

6. HAYEK, F. (1998) Los fundamentos de la libertad. Sexta edición (edición original en ingles 1959). Guatemala. Unión Editorial S.A.

7. HUERTA DE SOTO, J. (2014) Ensayos de economía política. España. Unión Editorial S.A.

8. KRUGMAN, P. \& WELLS, R.(2013) Microeconomía. Tercera edición. Barcelona. Editorial Reverté S.A.

9. MENGER, C. (2013) Principios de economía política. Segunda edición (edición original 1871). España. Unión Editorial S.A.

10. MISES, L. (2011) Política económica. Décima edición (edición original 1959). España. Unión Editorial S.A.

11. ROTHBARD, M. (2011) El hombre, la economía y el Estado. Tratado sobre principios de Economía. Volumen I (edición original 2004). España. Unión Editorial S.A.

12. SMITH, A. (2013) La teoría de los sentimientos morales. Tercera edición (edición original 1759). España. Alianza Editorial S.A.

13. SMITH, A. (2011) Riqueza de las naciones. Tercera edición (edición original 1776). España. Alianza Editorial S.A. 